\title{
INTERFERENSI DAN INTEGRASI KATA-KATA DAERAH DAN ASING DALAM NOVEL 'DIAN YANG TAK KUNJUNG PADAM'
}

\author{
Zaidatul Arifah \\ Sekolah Tinggi Agama Islam Nahdlatul Ulama (STAINU) Temanggung \\ Email: zaidarifah1985@gmail.com
}

\begin{abstract}
Abstrak
Tujuan dari penelitian ini adalah untuk menemukan interferensi dan integrasi kata-kata daerah dan asing dalam novel Dian yang Tak Kunjung Padam karya Sutan Takdir Alisjahbana. Selain itu, penelitian ini juga bertujuan mendeskripsikan hasil dari penelusuran interferensi kata/frasa daerah dan asing dalam novel tersebut. Penelitian ini dilakukan dengan menggunakan metode deskriptif kualitatif dengan teknik pengumpulan data studi pustaka. Hasil penelitian menunjukkan bahwa terdapat interferensi dan integrasi dalam novel Dian yang Tak Kunjung Padam. Berdasarkan data yang tekumpul, ditemukan kata integrasi sebanyak 88,7\% dan kata interferensi sebanyak 11,43\%. Interferensi dan integrasi bahasa dalam novel ini berasal dari bahasa Arab, Inggris, dan Palembang.
\end{abstract}

Kata Kunci: Interferensi, Integrasi, Sutan Takdir Alisjahbana.

\section{PENDAHULUAN}

Adanya kedwibahasaan akan menimbulkan adanya interferensi dan integrasi bahasa. Interferensi bahasa yaitu penyimpangan norma kebahasaan yang terjadi dalam ujaran dwibahasawan karena keakrabannya terhadap lebih dari satu bahasa, yang disebabkan karena adanya kontak bahasa. Saling mempengaruhi antarbahasa pasti terjadi, misalnya adanya proses peminjaman kosakata bahasa lain yang dikuasai oleh dwibahasawan tersebut.

Dalam novel Dian yang Tak Kunjung Padam diindikasikan terdapat interferensi dan integrasi kata/frasa. Hal itu disebabkan fenomena yang terjadi dalam konteks Bahasa Indonesia selalu berubah setiap periode tertentu. Novel Dian yang Tak Kunjung Padam ditulis pada tahun 1932. Pada masa itu Indonesia belum merdeka seperti sekarang. Bahasa Indonesia pada waktu itu masih berusia 4 tahun setelah peresmian pada tahun 1928. Bahasa Indonesia masih kental dengan aroma bahasa asing dan bahasa daerah untuk selanjutnya diramu menjadi bahasa Indonesia.

Novel Dian yang Tak Kunjung Padam sebagai hasil karya sastra yang dihasilkan pada masa itu juga mempunyai bahasa yang masih berbaur dengan bahasa daerah dan bahasa asing. Pembauran tersebut bisa juga dalam bentuk interferensi dan integrasi. Berdasarkan permasalahan itulah maka dilakukan interferensi dan integrasi kata/frasa dalam novel tersebut.
Terdapat penelitian yang sejalan dengan penelitian ini adalah Interferensi dan Integrasi Bahasa dalam Novel Tentang Kamu Karya Tere Liye (Kajian Sosiolinguistik) oleh Fiqih Rosyalia Humairoh. Selain itu terdapat penelitian lain yang serupa yaitu Interferensi Bahasa Indonesia dalam Bahasa Jawa pada Album Campursari Tresna Khutha Bayu oleh Novita Dyan Sekartaji.

Tujuan dari penelitian ini adalah untuk menemukan interferensi dan integrasi kata-kata daerah dan asing dalam novel Dian yang Tak Kunjung Padam karya Sutan Takdir Alisjahbana. Selain itu juga penelitian ini bertujuan mendeskripsikan hasil dari penelusuran interferensi kata/frasa daerah dan asing dalam novel tersebut, yang dirinci sebagai berikut. Pertama, memperoleh informasi besarnya intensitas interferensi dan integrasi leksikal bahasa lain, misalnya bahasa asing dan daerah terhadap bahasa Indonesia, khususnya dalam novel Dian yang Tak Kunjung Padam karangan Sutan Takdir Alisjahbana. Kadua, mengetahui asal bahasa dari bahasa yang di serap, baik secara interferensi maupun integrasi dalam novel Dian yang Tak Kunjung Padam karangan Sutan Takdir Alisjahbana. Ketiga, memperoleh informasi besarnya intensitas bahasa lain (asing dan daerah), yang telah diintegrasikan ke dalam bahasa Indonesia, khususnya dalam novel Dian yang Tak Kunjung Padam karangan Sutan Takdir Alisjahbana. 
April 2020 Jurnal Pendidikan Bahasa dan Sastra Indonesia

\section{METODE PENELITIAN}

Penelitian ini dilakukan dengan menggunakan metode deskriptif kualitatif dengan teknik pengumpulan data studi pustaka. Adapun sumber data yang diperlukan dalam penelitian ini adalah berupa interferensi kata-kata asing dan daerah yang diperoleh melalui penelusuran dalam novel Dian yang Tak Kunjung Padam karya Sutan Takdir Alisjahbana. Langkah-langkah dalam penelitian ini adalah mencari kata-kata serapan dari bahasa asing dan daerah yang terdapat dalam novel Dian yang Tak Kunjung Padam karangan Sutan Takdir Alisjahbana. Katakata serapan tersebut dianalisis secara deskriptif, baik pada kata yang telah diintegrasikan ke dalam Bahasa Indonesia maupun kata yang bersifat interferensi. Selanjutnya, kata-kata tersebut dianalisis dari aspek perubahan dan pergeseran maknanya. Setelah ditemukan integrasi dan interferensi kata, dilakukan pencatatan pada setiap kata. Kemudian kata-kata tersebut diklasifikasikan sesuai dengan penggolongan interferensi dan integrasi.

\section{HASIL DAN PEMBAHASAN}

Interferensi menurut Jendra adalah gejala penyusupan sistem suatu bahasa ke dalam bahasa lain (1991:187). Sedangkan integrasi adalah penggunaan unsur bahasa lain secara sistematis seolah-olah merupakan bagian dari suatu bahasa tanpa disadari oleh pemakainya (Kridalaksana, 1998:84).

Interferensi dan integrasi merupakan hal yang berbeda. Weinrich (1970:11) mengemukakan bahwa integrasi bahasa terjadi apabila suatu interferensi dilakukan secara terus-menerus sehingga semakin diterima sebagai bagian dari sistem bahasa mereka. Berdasarkan hal ini, dapat diketahui bahwa yang membedakan antara interferensi dan integrasi bahasa adalah kamus. Apabila suatu kata serapan belum tercantum dalam kamus, maka kata tersebut dikatakan sebagai interferensi. Namun jika sebuah kata sudah tercantum dalam kamus, maka disebut sebagai kata yang sudah terintegrasi.

Peneliti menemukan sebanyak 34 kata interferensi dan integrasi dalam novel. Pada tabel-tabel di bawah ini dipaparkan 10 contoh kosakata-kosakata dalam novel Dian yang Tak Kunjung Padam yang diserap dari bahasa lain beserta analisisnya.
Data 1

\begin{tabular}{|c|c|c|}
\hline \begin{tabular}{|l|} 
ASAL \\
KATA
\end{tabular} & $\begin{array}{l}\text { URAIAN } \\
\text { FRASA }\end{array}$ & ANALISIS KATA/ \\
\hline \multirow[t]{9}{*}{ Dunia } & Kalimat & $\begin{array}{llr}\text { Adinda } & \text { tak } & \text { hendak } \\
\text { menurutkan } & \text { nafsu } \\
\text { keduniaan } & \text { sehingga } \\
\text { merendahkan derajat cinta } & \text { kakanda yang tinggi dan } \\
\text { mulia itu. (hlm. 143) }\end{array}$ \\
\hline & Asal Bahasa & Bahasa Arab \\
\hline & Bentuk Asal & Dunya \\
\hline & Arti & Alam kehidupan \\
\hline & $\begin{array}{l}\text { Penggunaan } \\
\text { dalam Novel }\end{array}$ & keduniaan \\
\hline & Arti & $\begin{array}{l}\text { Bumi dengan segala sesuatu } \\
\text { yang terdapat diatasnya }\end{array}$ \\
\hline & Bentuk & Kata berimbuhan \\
\hline & Sinonim & - \\
\hline & & \\
\hline
\end{tabular}

Data 2

\begin{tabular}{|c|c|c|}
\hline \begin{tabular}{|l|} 
ASAL \\
KATA
\end{tabular} & $\begin{array}{l}\text { URAIAN } \\
\text { FRASA }\end{array}$ & DAN ANALISIS KATA/ \\
\hline \multirow[t]{9}{*}{ Derajat } & Kalimat & $\begin{array}{l}\text { Adinda tak hendak } \\
\text { menurutkan nafsu keduniaan } \\
\text { sehingga } \quad \text { merendahkan } \\
\text { derajat cinta kakanda yang } \\
\text { tinggi dan mulia itu. (hlm. } \\
\text { 143) }\end{array}$ \\
\hline & Asal Bahasa & Bahasa Arab \\
\hline & Bentuk Asal & Darojat \\
\hline & Arti & Tingkat \\
\hline & $\begin{array}{l}\text { Penggunaan } \\
\text { dalam Nove }\end{array}$ & Derajat \\
\hline & Arti & Martabat \\
\hline & Bentuk & Kata Dasar \\
\hline & Sinonim & Pangkat \\
\hline & Status & Integrasi \\
\hline
\end{tabular}

Data 3

\begin{tabular}{|c|c|c|}
\hline $\begin{array}{l}\text { ASAL } \\
\text { KATA }\end{array}$ & \begin{tabular}{|l|} 
URAIAN \\
FRASA
\end{tabular} & ANALISIS KATA/ \\
\hline \multirow[t]{9}{*}{ Kerabat } & Kalimat & $\begin{array}{l}\text { Dimuka terbayang-bayang } \\
\text { makam yang baru di Candi } \\
\text { Balang dalam lingkungan } \\
\text { tembok pekuburan kaum } \\
\text { kerabat Raden Mahmud itu. } \\
\text { (hlm. 154) }\end{array}$ \\
\hline & Asal Bahasa & Bahasa arab \\
\hline & Bentuk Asal & Qorib \\
\hline & Arti & Dekat \\
\hline & $\begin{array}{l}\text { Penggunaan } \\
\text { dalam Novel }\end{array}$ & Kerabat \\
\hline & Arti & $\begin{array}{l}\text { Keturunan dari induk yang } \\
\text { sama yang dihasilkan dari } \\
\text { gamet yang berbeda }\end{array}$ \\
\hline & Bentuk & Kata dasar \\
\hline & Sinonim & Dekat \\
\hline & Status & Interferensi \\
\hline
\end{tabular}

E-ISSN 2528-6684, ISSN 2528-4371 
Data 5

\begin{tabular}{|c|c|c|}
\hline $\begin{array}{l}\text { ASAL } \\
\text { KATA }\end{array}$ & $\begin{array}{l}\text { URAIAN } \\
\text { FRASA }\end{array}$ & DAN ANALISIS KATA/ \\
\hline \multirow[t]{9}{*}{ Ruh } & Kalimat & $\begin{array}{llr}\text { Ruh itu } & \text { harus } & \text { dijaganya } \\
\text { supaya tinggal suci } & \text { selama- } \\
\text { lamanya, } & \text { supaya } & \text { jangan } \\
\text { menjadi } & \text { cemar } & \text { pula, } \\
\text { sehingga } & \text { tiada } & \text { layak } \\
\text { menerima } & \text { cinta } & \text { Yasin lagi. } \\
\text { (hlm. 121) } & & \end{array}$ \\
\hline & Asal Bahasa & Bahasa Arab \\
\hline & Bentuk Asal & Ruh \\
\hline & Arti & Nyawa \\
\hline & $\begin{array}{l}\text { Penggunaan } \\
\text { dalam Novel }\end{array}$ & Ruh \\
\hline & Arti & $\begin{array}{l}\text { Sesuatu (unsur) yang ada } \\
\text { dalam jasad yang diciptakan } \\
\text { Tuhan sebagai sebab adanya } \\
\text { hidup (kehidupan) }\end{array}$ \\
\hline & Bentuk & Kata dasar \\
\hline & Sinonim & Nyawa \\
\hline & Status & Interferensi \\
\hline
\end{tabular}

Data 6

\begin{tabular}{|c|c|c|}
\hline $\begin{array}{l}\text { ASAL } \\
\text { KATA } \\
\end{array}$ & $\begin{array}{l}\text { URAIAN } \\
\text { FRASA }\end{array}$ & DAN ANALISIS \\
\hline \multirow[t]{9}{*}{ Fana } & Kalimat & $\begin{array}{l}\text { Sebelum ia bertemu muka } \\
\text { dengan kekasihnya itu, ia } \\
\text { belum rela lagi akan } \\
\text { meninggalkan dunia fana ini. } \\
\text { (hlm. 123) }\end{array}$ \\
\hline & Asal Bahasa & Bahasa Arab \\
\hline & Bentuk Asal & Fana \\
\hline & Arti & : Tidak kekal \\
\hline & $\begin{array}{l}\text { Penggunaan } \\
\text { dalam Novel }\end{array}$ & :Fana \\
\hline & Arti & : Tidak kekal \\
\hline & Bentuk & Kata dasar \\
\hline & Sinonim & $:-$ \\
\hline & Status & Integrasi \\
\hline
\end{tabular}

Data 19

\begin{tabular}{|c|c|c|}
\hline $\begin{array}{l}\text { ASAL } \\
\text { KATA }\end{array}$ & \multicolumn{2}{|l|}{$\begin{array}{l}\text { URAIAN } \\
\text { FRASA } \\
\end{array}$} \\
\hline \multirow[t]{7}{*}{ Bordel } & Kalimat & $:\left(\begin{array}{l}\text { Seakan-akan tak puas ia } \\
\text { sendiri mengamati dirinya } \\
\text { dengan baju pendek yang } \\
\text { bertepikan renda bordel itu. } \\
\text { (hlm. 57) }\end{array}\right.$ \\
\hline & Asal Bahasa & : Bahasa Palembang \\
\hline & Bentuk Asal & : $\mid$ Bordel \\
\hline & Arti & $: \begin{array}{l}\text { Bordir, hiasan dari benang } \\
\text { yang dijahitkan pada kain }\end{array}$ \\
\hline & $\begin{array}{l}\text { Penggunaan } \\
\text { dalam Novel }\end{array}$ & $:$ Bordel \\
\hline & & $\begin{array}{l}\text { Bordir, hiasan dari benang } \\
\text { yang dijahitkan pada kain }\end{array}$ \\
\hline & Bentuk & : Kata dasar \\
\hline
\end{tabular}

\begin{tabular}{|l|l|l|l|}
\hline & Sinonim & $:$ & Sulam \\
\hline & Status & $:$ & Integrasi \\
\hline
\end{tabular}

Data 28

\begin{tabular}{|c|c|c|}
\hline $\begin{array}{l}\text { ASAL } \\
\text { KATA }\end{array}$ & $\begin{array}{l}\text { URAIAN } \\
\text { FRASA }\end{array}$ & DAN ANALISIS \\
\hline \multirow{9}{*}{ Halte } & Kalimat & $: \mid \begin{array}{l}\text { Rumahnya terletak tiada } \\
\text { berapa jauh dari halte kecil } \\
\text { di tepi dusun itu. (hlm. 19) }\end{array}$ \\
\hline & Asal Bahasa & : Bahasa Inggris \\
\hline & Bentuk Asal & : Halte \\
\hline & Arti & : Perhentian \\
\hline & $\begin{array}{l}\text { Penggunaan } \\
\text { dalam Novel }\end{array}$ & : Halte \\
\hline & Arti & $: \mid \begin{array}{l}\text { Perhentian kereta api, trem, } \\
\text { atau bus (biasanya } \\
\text { mempunyai ruang tunggu } \\
\text { yang beratap, tetapi lebih } \\
\text { kecil dari stasiun. }\end{array}$ \\
\hline & Bentuk & : Kata dasar \\
\hline & Sinonim & $:$ - \\
\hline & Status & : Integrasi \\
\hline
\end{tabular}

Data 32

\begin{tabular}{|c|c|c|}
\hline $\begin{array}{l}\text { ASAL } \\
\text { KATA }\end{array}$ & $\begin{array}{l}\text { URAIAN } \\
\text { FRASA }\end{array}$ & DAN ANALISIS \\
\hline \multirow[t]{9}{*}{ Adat } & Kalimat & $\mid \begin{array}{l}\text { Pagi-pagi serupa itu ialah } \\
\text { waktu perawan-perawan } \\
\text { Palembang mandi. Menurut } \\
\text { adat mereka tidak boleh } \\
\text { memperlihatkan dirinya, } \\
\text { tidak boleh keluar rumah. } \\
\text { (hlm. 3) }\end{array}$ \\
\hline & Asal Bahasa & Bahasa Arab \\
\hline & Bentuk Asal & : Adat \\
\hline & Arti & : Kebiasaan \\
\hline & $\begin{array}{l}\text { Penggunaan } \\
\text { dalam Novel }\end{array}$ & $:$ Adat \\
\hline & Arti & $: \begin{array}{l}\text { Aturan (perbuatan, dsb) yang } \\
\text { lazim diturut atau dilakukan } \\
\text { sejak dahulu }\end{array}$ \\
\hline & Bentuk & : Kata dasar \\
\hline & Sinonim & : Kebiasaan \\
\hline & Status & : Integrasi \\
\hline
\end{tabular}

Data 33

\begin{tabular}{|c|c|c|}
\hline $\begin{array}{l}\text { ASAL } \\
\text { KATA } \\
\end{array}$ & $\begin{array}{l}\text { URAIAN } \\
\text { FRASA }\end{array}$ & DAN ANALISIS KATA/ \\
\hline \multirow[t]{5}{*}{ Ambin } & Kalimat & $: \mid \begin{array}{l}\text { “Ah, tidak, Bu!” jawab } \\
\text { Molek dengan kemalu- } \\
\text { maluan dan ia pun pergi } \\
\text { tergesa-gesa ke ambin akan } \\
\text { berpakaian. (hlm. 7) }\end{array}$ \\
\hline & Asal Bahasa & : Bahasa Palembang \\
\hline & Bentuk Asal & : Ambin \\
\hline & Arti & : Balai-balai \\
\hline & $\begin{array}{l}\text { Penggunaan } \\
\text { dalam Novel }\end{array}$ & $:$ Ambin \\
\hline
\end{tabular}




\begin{tabular}{|l|l|l|}
\hline Bentuk & $:$ & Balai-balai \\
\hline Sinonim & $:$ & - \\
\hline Status & $:$ & Integrasi \\
\hline
\end{tabular}

Data 34

\begin{tabular}{|c|c|c|c|}
\hline $\begin{array}{l}\text { ASAL } \\
\text { KATA } \\
\end{array}$ & \multicolumn{3}{|c|}{ URAIAN DAN ANALISIS KATA/FRASA } \\
\hline \multirow[t]{9}{*}{ Wajah } & Kalimat & & $\begin{array}{l}\text { Wajah anak gadis bangsawan } \\
\text { itu senantiasa terbayang pada } \\
\text { matanya, seperti telah serupa } \\
\text { itu semestinya. (hlm. 13) }\end{array}$ \\
\hline & Asal Bahasa & & Bahasa Arab \\
\hline & Bentuk Asal & & Wajhu \\
\hline & Arti & & Bagian depan dari kepala \\
\hline & $\begin{array}{l}\text { Penggunaan } \\
\text { dalam Novel }\end{array}$ & & Wajah \\
\hline & Arti & & Bagian depan dari kepala \\
\hline & Bentuk & & Kata dasar \\
\hline & Sinonim & & Muka \\
\hline & Status & & Interferensi \\
\hline
\end{tabular}

Padam karya Sutan takdir alisjahbana terjadi/ditemukan data yang berupa kata-kata interferensi dan integrasi. Dari novel ini ditemukan data berjumlah 34. Berdasarkan data tersebut didapatkan lebih banyak kata integrasi daripada interferensi. Dari 34 kata serapan, ditemukan kata integrasi sebanyak 88,7\% dan kata interferensi sebanyak 11,43\%.

Berdasarkan angka persentase jumlah interferensi dan integrasi bahasa dalam novel ini, diketahui bahwa lebih banyak integrasi kata yang muncul daripada interferensinya. Hal ini membuktikan bahwa penetapan bahasa asing maupun daerah sehingga menjadi Bahasa Indonesia (terlulis dalam kamus) juga begitu cepat. Interferensi bahasa yang muncul lebih sedikit daripada integrasinya memperlihatkan bahwa proses peralihan dari interferensi bahasa menjadi integrasi juga lebih cepat.

Kata-kata interferensi dan integrasi dalam novel didapat sebanyak 34 kata. Kata-kata ini diperoleh dari hasil penelusuran sebanyak 156 halaman, sehingga ditemukan rata-rata satu kata dalam 4 halaman novel. Berdasarkan hal ini dapat diketahui bahwa Bahasa Indonesia adalah bahasa yang kaya akan kosakata. Interferensi dan integrasi muncul hanya pada saat muncul dalam kalimat-kalimat yang memerlukannya saja.

Adapun sumber interferensi dan integrasi berasal dari bahasa Arab, bahasa Inggris, dan bahasa Palembang.Yang menjadi pendorong penggunaan interferensi dan integrasi dalam novel tersebut adalah latar dari novel itu sendiri yaitu sungai Musi Palembang. Di sana masih kental dengan adat keislaman, sehingga banyak istilah-istilah Islam yang muncul dalam novel tersebut. Selain itu, penggunaan interferensi dan integrasi didorong oleh latar belakang pengarang novel sendiri yang berasal dari daerah Minangkabau yang masih kental dengan bahasa Melayu.

Interferensi dan integrasi bahasa asing dalam novel karya Sutan Takdir ini berasal dari bahasa Arab dan Inggris. Latar belakang kehidupan pengarang ikut berperan dalam munculnya interferensi dan integrasi bahasabahasa tersebut dalam novelnya. Ia memiliki pengetahuan agama dan hukum yang luas. Sehingga bahasa Arab menjadikannya kaya dengan interferensi dan integrasi bahasa Arab. Begitu pula dengan bahasa Inggris, ia adalah sastrawan berpendidikan tinggi sehingga telinganya tidak asing dengan bahasa Inggris.

Interferensi dan integrasi bahasa daerah pada novel Dian yang Tak Kunjung Padam berasal dari bahasa daerah Palembang. Sutan Takdir lahir di Sumatera Utara. Kebanyakan penduduk di sana (kala itu) menggunakan bahasa Palembang sebagai bahasa ibu. Dengan demikian interferensi dan integrasi bahasa daerah dalam novel ini adalah bahasa daerah Palembang.

\section{SIMPULAN}

Dari pemaparan di atas dapat disimpulkan bahwa dalam novel berjudul Dian yang Tak Kunjung Padam karya Sutan takdir Ali Syahbana terdapat beberapa interferensi dan integrasi bahasa. Adapun intensitas integrasi terlihat lebih banyak daripada interferensi. Adanya interferensi dan integrasi dalam novel ini memperlihatkan bahwa Sutan Takdir merupakan pengarang yang kaya bahasa. Pengarang mampu memadupadankan antara serapan bahasa asing dan daerah untuk disandingkan dengan Bahasa Indonesia yang bukan serapan.

Dilihat dari sumber interferensi dan integrasi novel ini menunjukkan bahwa kata serapan sudah banyak digunakan pada masa terbitnya novel ini (Arab, Inggris, dan Palembang). Hal ini membuat novel memiliki karakter yang kuat, yakni interferensi dan integrasi bahasa asing menumbuhkan keakraban karya dengan pembaca yang berbahasa modern (saat itu) dan bahasa daerah menunjukkan bahwa suasana dalam novel sangat dekat dengan kearifan lokal berlatar Palembang. 


\section{REFERENSI}

Alisjahbana, S. Takdir. 2008. Dian yang Tak Kunjung Padam. Jakarta: Dian Rakyat.

eprints.uny.ac.id/44493/1/Novita\%20\%Dyah20Se kartaji_07205244127.PDF

Humairoh, Fiqih Rosyalia. 2018. Interferensi dan Integrasi Bahasa dalam Novel Tentang Kamu Karya Tere Liye (Kajian Sosiolinguistik). Tangerang Selatan: Universitas Pamulang. Diakses dari: eprints.unpam.ac.id/4834

https://kbbi.kemdikbud.go.id/
Jendra, I Wayan. 1991. Dasar-Dasar Sosiolinguistik. Denpasar: Ikayana.

Kridalaksana, Harimurti. 1988. Introduction to Word Formation and Word Classes. Jakarta: Universitas Indonesia

Ramirez, Arnulfo G., 1985. Bilingualism Throught Schooling: Cross Cultural Education for Minority and Majority Student. New York: State University of Newyork Press.

Rusyana, Yus. 1988. Perihal Kedwibahasaan (Bilingualisme). Jakarta: Depdikbud. 
Volume 5 No. 1 METALINGUA

April 2020 Jurnal Pendidikan Bahasa dan Sastra Indonesia 